\title{
Cultura, globalização e consumo: notas sobre a criatividade e inventividade musical no Recife das décadas de 1980 e 1990
}

\section{Walter Ferreira de França Filho*}

walrcf@gmail.com

\begin{abstract}
Resumo
Este texto proporciona notas para um debate acerca das práticas de produção artísticas no Recife entre o final da década de 1980 e os anos 1990. Há existência até a atualidade de uma ideia de certa irrupção com o marasmo existente no Recife antes do movimento Manguebeat em meados dos anos 1990. O texto pretende apontar contribuições e criatividade de artistas, sobretudo no âmbito afro-musical recifense da década de 1980, considerando suas relações e se de algum modo contribuíram para a badalada década de 1990 dos mangueboys. A proposta de análise é subsidiada por apontamentos realizados em trabalhos sobre o movimento Manguebeat no Recife. Essas notas reflexivas sobre as décadas destacadas, sem sombra de dúvidas, não vêm contestar a criatividade dos idealizadores do referido movimento, no entanto propor estudos no qual possamos reavaliar os postulados de que havia, ali, na cidade do Recife, um relativo marasmo. Analisaremos como fontes os periódicos de Pernambuco, trabalhos acadêmicos e a bibliografia pertinente ao tema. Como referencial teórico, pensaremos por meio da concepção de "cultura como recurso" do George Yúdice em a Conveniência da cultura.
\end{abstract}

\section{Palavras-chave}

Manguebeat; Cultura pernambucana; Negritude

\begin{abstract}
This text provides points for a debate around the artistic production in Recife between the late 1980s and the 1990s. There exist up until today ideas about a certain eruption within the existing cultural vacuum before the Manguebeat Movement in the middle of the 1990s. This text intends to point out the contributions and creativity of artists, above all within the Afro-musical scope of Recife in the 1980s, and to consider its relationship with and contributions to the celebrated decade of the Mangueboys in the 1990s. The proposition of this analysis is subsidized by documented testimonies from various academic works about the Manguebeat Movement of Recife. These reflective notes about these prominent decades are in no way meant to question the creativity of the idealizers of the aforementioned movement, but instead propose studies in which we can reevaluate the idea that there was a relative cultural vacuum that existed in the city of Recife. As sources we will analyze the periodicals of Recife, academic works and a pertinent bibliography to the theme. As a theoretic reference, we should think in terms of George Yudice's concept of "culture as a resource" in his work The Expediency of Culture.
\end{abstract}

\section{Keywords}

Manguebeat; Culture of Pernambuco; Negritude.

*Graduado e especialista em História pela Universidade Católica de Pernambuco. Mestrando em História pelo PPGH - UFPE. Bolsista do Conselho Nacional de Desenvolvimento Científico e Tecnológico - CNPq. 


\section{Introdução}

O ano é 2017, vinte anos após a morte do maior expoente do movimento artístico e musical, ocorrido na cidade do Recife, na década de 1990, Chico Science. Talvez um ótimo momento de voltar os olhos para esse período, que, segundo diversos jornalistas, artistas e pesquisadores, de maneira direta ou indireta, endossam a opinião de que o "ressurgimento" de diversas manifestações da "dita" cultura popular pernambucana se deve ao Movimento Manguebeat (TELES, 2003; 2012) (LEÃO, 2002); (OLIVEIRA, 2012) (RIBEIRO, 2007) (SILVEIRA， 2002) (NETO, 2001; 2003) (NASCIMENTO， 2010) (DUNEMAN， 2002) (GALINSKY, 1998). Porém, esse movimento não ocorre sem ter havido críticas e ressentimentos. Artistas contestam, reivindicam e se inserem como participes de um momento produtivo musical local. Em outras ocasiões, negam até mesmo o rótulo 'Mangue' (BANDAS REGEITAM..., 1999, p. 1). Iremos, neste artigo, comentar momentos, a nosso ver, relevantes para refletir a criatividade 'estourada' na década de 1990, lançando olhares a décadas anteriores, analisando, sobretudo o que ocorria na década de 1980.

Por meio da construção de um símbolo, aludindo ao manguezal e a toda riqueza nele existente, o caranguejo, crustáceo que vive nesse bioma, ganhou outros sentidos a partir do 'Manifesto Mangue'. Esse animal, nas metáforas deste texto, ganhou cérebro, o Chamagnathus Granulatus sapiens. Ora, se antes o caranguejo possuía a função de alimento para as famílias pobres que vivem às margens dos rios próximos ao mar, bem como servir de iguaria aos turistas que visitam o Recife, agora é o símbolo escolhido para representar o movimento. Metaforicamente, o caranguejo é a representação do ciclo vital do mangue, do caranguejo que come os dejetos humanos despejados naquele local, e que depois se transforma novamente em alimento.
Assim como a cultura se transforma em um processo de movimento perpétuo.

Até o estouro desse movimento, eram jovens desconhecidos... Falavam palavras não muito populares e produziam seu som, bastante peculiar... Diziam em suas músicas frases e nomes que, em tempos recentes, possuíam outros significados... Perna Cabeluda, Galeguinho do Coque, Biu do Olho Verde... Eis alguns elementos do movimento artístico cultural denominado Manguebeat, que povoou o cenário recifense com toda força ao longo dos anos 1990. Do tipo moda, artes plásticas, música... Contextos variados trazendo uma verdadeira mixórdia complexa e, ao mesmo, tempo profícua.

O Diário de Pernambuco, em 1990, apresentou as seguintes matérias: "Recife entre as piores cidades, diz instituto" (1990, p. 16) e "Título de cidade miserável divide recifenses." (1990, p. 10) Notas que apresentavam o Recife como uma cidade miserável, um dos piores lugares de se viver. E essas mesmas palavras se tornavam cada vez mais presentes perante a população recifense. Aquela realidade lida e vivida por diversos habitantes da Cidade deveria mudar. Os aspectos de "cidade miserável" adotado nos discursos e músicas dos mangueboys eram justificados no release/manifesto para evidenciar a real necessidade de movimentar a cidade. Diziam eles que a cidade estava sofrendo um infarto por falta de ações políticas e culturais. Suas músicas expunham o cotidiano da cidade, críticas sociais em tons irônicos como as existentes nas músicas das bandas Chico Science \& Nação Zumbi e Mundo Livre S/A. Parte dos jovens pernambucanos não conhecia ou não se interessava pelas manifestações tradicionais existente em Pernambuco. As bandas de rock/pop pernambucanas adotaram a "trilha das misturas", reivindicando para si a responsabilidade sobre o resgate de tradições que corriam/correm risco de deixar de existir. 
Dessa maneira, cada vez mais jovens participam da vida cultural da cidade e das manifestações culturais tradicionais como Maracatus, Ciranda, Cavalo Marinho, entre outras manifestações. Em alguns discursos, eram citados como fonte de inspiração para as bandas do cenário Manguebeat. Manifestações, antes relegados a moradores da periferia e interior, passam a contar com a participação e interesse cada vez maior de pessoas da camada média urbana da cidade. No entanto, na década anterior, percebemos movimentações de artistas que realizavam combinações musicais e cênicas com elementos da cultura popular ${ }^{1}$.

As questões acima destacadas ganham ares de complexidade quando, no final da década de 1990, alguns grupos antes identificados como partícipes do Movimento Manguebeat declararam o não pertencimento ao movimento. A morte de Chico Science parece ter sido um divisor de águas na relação entre os ditos magueboys, como pode ser lido em algumas matérias em jornais no final da década de 1990 (LINS, 1999, p. 1) (SANTOS, 1999, p. 1) (SALEM, 2000, p. 06) (SALEM, 1999, p. 1). Ora, então a cena musical pernambucana deixa de existir com a morte de seu líder maior, Chico Science? Afinal de contas, o que ocorreu nesse período? Pode-se atribuir ao Movimento Manguebeat responsabilidade por tudo isso? Não acontecia nada, ninguém se movimentava antes? O que acontecia no Recife da década anterior? Seria hora para refletir os diversos trabalhos que abordam o Movimento Manguebeat?

\section{Efervescências Culturais no Recife}

Por meio da matéria "Chico Science "envenena" o maracatu" do Jornal Folha de São Paulo, podemos sentir de que maneira era visto o referido movimento relacionado à cultura local. Segundo o jornalista Luís Antônio Giron, Chico Science teria declarado que estava "resgatando" as manifestações culturais “populares" (GIRON, 1994, p. 5). Era o resgate das "coisas da terra", "injetando energia” em manifestações culturais que, segundo ele, estavam esquecidas. Suas letras aludiam ao cotidiano do Recife, elencando as características desta cidade, misturando lama do manguezal com ritmos de Pernambuco juntamente com o pop rock mundial. Surge assim a metáfora da parabólica fincada na lama, por meio dela é explicada a recepção de informações captadas por meio da parabólica, captando as ideias do mundo globalizado, capturado via satélite, e com isso conectando a Manguetown ao mundo.

O ponto de partida deste movimento pode ser atribuído ao momento da criação, em 1991, do releasel manifesto intitulado "Caranguejos com cérebro", assinado por Fred Zero Quatro e Renato L ${ }^{2}$. Esse manifesto, apresentado como o definidor das principais ideias do movimento, pode ser encontrado no encarte do $\mathrm{Cd}$ Da Lama ao caos, da banda "Chico Science e Nação Zumbi”, lançado em 1994, pelo selo Chaos/ Sony Music. Tanto em vida, como também depois de sua morte, Chico e sua obra, juntamente com o Manguebeat, continuam a ser vistos como a maior contribuição cultural de Pernambuco nos anos 1990. E foi esse o período de auge do movimento, que coincide com a ascensão das ma-

\footnotetext{
${ }^{1}$ VER: Diário Pernambuco, 08/01/1985, p. b6; Diário Pernambuco”. 13/02/1985, p. a5; Diário Pernambuco, 20/02/1985 p. a15.

${ }^{2}$ Fred Zero Quatro é compositor e líder da banda Mundo Livre S/A. Também é formado em Jornalismo, com uma carreira já engatilhada, abdicou da rotina dos jornais para dedicar-se à música. Fred é autor do manifesto mangue, Caranguejos com cérebro, escrito entre 1991 e 1992 . Pode ser apontado, juntamente com Chico Science, o responsável pela criação do Movimento Manguebeat. Nasceu no dia 11/06/1965, em Jaboatão do Guararapes, Pernambuco. Renato Lins, ou Renato L, é jornalista, radialista, produtor e coautor do Manifesto mangue. Também foi secretário de cultura do Recife durante a gestão do Prefeito João da Costa.
} 
nifestações culturais "populares” pernambucanas. Resgate, salvação de tradições... A quem interessar uma leve compulsada nos periódicos do Recife dos anos 1960 e 1970, vai lembrar que os discursos alusivos ao resgate das tradições e à salvação das manifestações culturais não constituíam novidade no cenário cultural da capital pernambucana (LIMA, 2012).

Uma das principais características do movimento reside na criação de performances baseadas em um modo de agir e vestir-se à maneira como Chico Science se apresentava nos palcos. Simples, extrovertido, desengonçado... Chico Science fazia uso de performances irreverentes, cantava aos pulos nos palcos, simulando gestos de um "caranguejo", trajando roupas coloridas e chapéus de palha. Esse chapéu, por exemplo, era característico de tipos "populares", a exemplo de feirantes, pescadores e pessoas simples de modo geral. Roupas, gestos, palavras, sinais, tudo perfazendo um contexto harmônico e de denúncia das péssimas condições de vida da capital pernambucana ${ }^{3}$. Tudo isso envolvia elementos da informática, em perfeita sintonia com a cultura "dita" psicodélica.

Ressalto que neste aspecto não há elementos tão novos. O psicodelismo, enquanto parte de uma estética, já havia sido motivo de movimentos anteriores, a exemplo do "Udigrudi", um movimento 'underground' ocorrido no Recife, nos anos 1970 (LUNA, 2010). Correndo riscos de ser contraditório, entretanto, devo reconhecer que há vários elementos inovadores no referido movimento. Mas podemos entendê-lo como parte de um contexto maior e bastante complexo. Sem querer explicar toda a história apenas a partir de suas relações com o "cruel" e "determinante" contexto (REVEL, 1998, p. 15 - 38.), é possível perceber que muito do que se fazia presente nos discursos, gestos e trejeitos do Manguebeat, já se encontravam presentes em movimentos anteriores.

O mundo pós-Segunda Guerra Mundial não foi mais o mesmo. Vivemos cenários de contestação, episódios significativos que alteraram as maneiras como os jovens observam os acontecimentos do mundo a sua volta. Durante a segunda metade do século XX, diversos movimentos de contestação às normas se seguiram durante as décadas posteriores. A década de 1960 foi bastante conturbada no Brasil e no mundo. Luta por direitos civis nos Estados Unidos, independências de inúmeros países do continente africano, além dos movimentos de agitações culturais na Europa davam a tônica do período. Por exemplo, o "I have a dream" (eu tenho um sonho), de Martin Luther King, que pregava a harmonia entre negros e brancos nos EUA, em seu discurso em 1963, questões referentes à liberdade e igualdade das mulheres (movimentos feministas) perante os homens, guerras, assassinato do presidente americano JF Kennedy, protestos em 1968, ditaduras instalando-se na América Latina, dentre outros eventos, constituem os anos 1960 .

Em meio ao turbilhão de acontecimentos existentes nos anos 1960, Recife também vivencia seus momentos de "ácidos lisérgicos", que antecederam os agitados anos 1970. Como não poderia deixar de ser, a capital pernambucana tem como palco o movimento Udigrudi, que apresenta vários elementos de composição de períodos anteriores, regados a muita contestação do momento em que viviam. Lula Cortes, Ave Sangria, dentre outros... Os hippies, assim como o Tropicalismo e o Udigrudi tiveram este cenário como fonte de intensas inspirações. Os Mangueboys também contestaram o período em que viveram. Em outras palavras, todo e qualquer movimento é fruto de outros que lhe antecede-

${ }^{3}$ Como se pode perceber na letra da música A Cidade: (...) A cidade não para, a cidade só cresce, o de cima sobe e o de baixo desce (...). Há uma junção de performances inovadoras, reunindo aspectos populares e psicodélicos, a serviço da denúncia das péssimas condições de vida da capital pernambucana. 
ram. Durante as duas últimas décadas do século XX, a música americana era a que mais possuía visibilidade, juntamente com outras tantas expressões musicais europeias. O mercado da música apresentava famosas bandas, e onde estavam as grandes gravadoras, produtores do Show Business e da World Music.

\section{Movimentação e Criatividade antes do Manguebeat: o campo afro-musical recifense}

As misturas, fusões entre o dito "local" e o "universal", dentre outros elementos, encontravam-se presentes nos movimentos que antecederam o Manguebeat, seja nas performances dos cantores Ívano ${ }^{4}$, Valdir Afonjá $^{5}$, dentre outros artistas durante a década de 1980, com o apoio do MNU, ou mesmo antes no Udigrudi. Entidades Negras de Pernambuco, por exemplo, promovem intervenções em diversos grupos culturais locais como afoxés e maracatus, maneira encontrada para fortalecer a cultura e a valorização do negro. Como descreve (LIMA, 2010, p. 312.):

Ao longo dos anos 1980 e 1990, as organizações e grupos políticos do movimento negro pernambucano estabeleceram estratégias de atuação nas entidades culturais, incentivando a criação de alguns e apoiando diretamente outros, participando inclusive de suas direções. Os casos mais emblemáticos são o do Maracatu Nação Leão Coroado (que teve a inter- venção do Movimento Negro Unificado entre os anos de 1986 e 1987, e do CEN$P E$ - Coletivo de Entidades Negras de Pernambuco, entre os anos de 1987 a 1989), e do Afoxé Alafin Oyó, que foi dirigido por alguns anos por Martha Rosa, militante do $M N U$.

Percebe-se que a década de 1980 vivenciou um movimento de valorização da cultura negra e popular, principalmente tomando a dianteira com artistas negros e entidades organizadas, reivindicando principalmente a igualdade racial e a valorização da negritude, como o MNU e CENPE. QUEIROS (2010) aponta que atuações de cantores como Ívano, Valdir Afonjá, Marcelo Santana, Brasáfrica, Favela Reggae foram importantes para a valorização da imagem e da cultura negra representada por sua musicalidade ${ }^{6}$. Diversos artistas que, em minha opinião, ajudaram a irrigar a semente da valorização das 'coisas da terra' com a música mundial. Da mesma maneira, fizeram os envolvidos no movimento artístico denominado Manguebeat na década de 1990.

Durante a década de 1980, tentativas de "salvar" o popular e o tradicional já se encontravam presentes em intervenções do Balé Popular do Recife ${ }^{7}$, Movimento Armorial ${ }^{8}$, Maracatu Nação Pernambuco ${ }^{9}$, Movimento Negro Unificado, entre outros grupos. Cada um, ao seu modo, tentou promover um composto de "resgate" e recriação das manifestações ditas tradicio-

\footnotetext{
${ }^{4}$ Nascido em 11/07/1963, no Recife, é cantor, compositor e ator. Sua carreira inicia durante a segunda metade dos anos 1970. Sua principal influência era a música negra, notadamente o reggae. Antes, em sua carreira solo, iniciada em 1984, acompanhado da banda Rebeldia, integrava a banda Flor da Terra, banda na qual teria iniciado seus experimentos e fusões de ritmos locais.

${ }^{5}$ Valdir Afonjá é músico nascido no Recife, em 20/08/1964. Participou de diversos eventos durante a década de 1980, inclusive propondo a mistura de elementos afromusicais com a world music.

${ }^{6}$ Podem ser constatados em matérias nos periódicos: Ívano faz show na Casa da Cultura. Jornal do Commercio, 01/02/1987, Caderno C, p. 07; Noite Afro-Olindense e Opção de amanhã no Centro de Arte. Jornal do Commercio. 07/02/1987, Caderno C. p. 06; Valdir Afonjá mostra em disco Negra Magia. Jornal do Commercio, 16/08/1988, Caderno C. Roteiro, p, 05; Valdir Afonjá faz novo show. Jornal do Commercio 14/01/1989 Caderno C, p. 06.

${ }^{7}$ O balé popular do Recife foi fundado em 1977. Grupo teatral que junta encenação e dança representando em inúmeros palcos as manifestações da cultura existente no nordeste brasileiro. Divulgando a cultura nordestina no Brasil e no Mundo.

${ }^{8}$ O Movimento Armorial surge nos anos 1970 no departamento de extensão cultural da UFPE com Ariano Suassuna e colaboradores. Com inspiração nas questões abordadas do cenário popular do Nordeste brasileiro, cria uma arte erudita partindo das raízes populares relacionando-se com outras áreas. A literatura (cordel), espetáculos teatrais (Mamulengos: bonecos movimentados por paus e cordas, Cavalo-marinho, Bumba-meu-Boi), pinturas (xilogravura), cinema, música (violão, rabeca, tambores), são alguns dos vários interesses do movimento com a arte. Surgido em âmbito universitário, teve apoio de órgão da administração pública como a Prefeitura do Recife e de outros artistas como Francisco Brennand e Raimundo Carrero. Também podemos citar como ressonâncias dele o Balé Armorial, Orquestra Armorial, Orquestra Romançal e Quinteto Armorial.

${ }^{9} \mathrm{O}$ grupo percussivo Nação Pernambuco é um grupo fundado em 1989 pelo bailarino Bernardino José e jovens de classe média envolvidos com dança, teatro e música. Este grupo percussivo de maracatu foi muito importante na movimentação cultural dos anos 1990. Ajudou a divulgar as batidas dos maracatus para a classe média do grande Recife, participando em diversos palcos de festivais em Pernambuco, Brasil e Mundo. Realizando além das apresentações nos palcos realizam desfiles nas ladeiras de Olinda e Recife Antigo.
} 
nais. Não nos esqueçamos de que Chico Science já perambulava pelas ruas de Peixinhos, quando visitava os ensaios da banda Lamento Negro, que, nos anos 1980, tocava samba reggae ao estilo cover das bandas baianas Muzenza e Olodum. Renato L recorda um dos momentos em que ele e amigos presenciaram as palavras de Chico Science ao regressar do ensaio da banda Lamento Negro. Segundo (LINS, 2015):

Na mesa acho que bebiam Mabuse, Fred, Vinicius Enter e outros. De repente, Chico apareceu e sem nem sentar foi anunciando "olha, fiz uma jam session com o pessoal do Lamento Negro e mesclei uma batida disso com uma batida daquilo e um baixo assim...Vou chamar esse groove de Mangue!

Entre tomar cervejas e escutar discos nas casas dos amigos, encontravam-se para ouvir musicas de artistas como James Brown, Jorge Bem, Afrika Bambaataa, entre outras. Suas experiências com aquelas batidas, aliadas com suas vivências no rock, rap e soul, permitiram-lhe pensar na criação de um ritmo formado a partir do encontro entre sons diferentes. Para o jornalista José Teles (2003; 2012), o Movimento Manguebeat, na década de 1990, irrompe com radicalidade inovadora do marasmo da década anterior. Teles apresenta, de maneira recorrente, o discurso que chamarei aqui de 'hiato cultural', referindo-se à década de 1980. Discordo do renomado jornalista do Jornal do Commercio pelo simples fato de considerar a movimentação artística de outro modo. Teles é um entusiasta do rock, e esse pop/ rock aliado aos elementos da globalização estourou na década de 1990 com o movimento Mangue, que encantou mentes e corações de jovens. Talvez o que tenha faltado, na década de 1980, seja o que Yúdice (2005) chama de 'um sistema de financiamento, de apoio'.
Mediante análises dos jornais pernambucanos dos anos 1980, notadamente Diário de Pernambuco e Jornal do Commercio, encontramos diversas notícias sobre as atuações de artistas articulando e experimentando outros estilos musicais com as ditas 'coisas da terra', ou seja, ritmos da cultura popular local. Percebese, por exemplo, que já existiam algumas propostas de combinações de ritmos em curso, propondo a fusão do afoxé com o maracatu, e desses com o reggae ${ }^{10}$. Durante a década de 1990, com os mangueboys, o rock and roll vai ser o som do momento, e objeto de combinação para as fusões com os ritmos locais, não mais será o reggae. Valdir Afonjá, em 1988, ressalta as características da música que sua banda apresentará no show do disco Negra Magia:

\begin{abstract}
Vai ser uma noite em que o som forte da mãe África será estrela principal. Não a música pseudo-afro 'from' Bahia (...) mas sim, o som marginal de Valdir Afonjá e que ele fez questão de realçar nesse seu primeiro disco 'Negra Magia' (...) Uma das principais responsáveis pela qualidade do som desse disco é a banda que toca com Valdir. Formado por músicos experientes e muito conhecidos no cenário musical local, o grupo dá mais elasticidade ao som produzido e executa com competência todas as Salsas, os reggaes, os sambas e os funks existentes ao longo de todas as faixas do 'negra magia'. 'Tereci' é um exemplo dessa fusão de ritmos onde do Aponijé (ritmo do candomblé) a Rebento passa para o calipso sem se perder ou fazer 'salada'. Em 'Black Soul' o reggae se funde com o funk, criando um ritmo totalmente negro [...] (JORNAL DO COMMERCIO, 16/08/1988, Caderno C, p. 05).
\end{abstract}

Estamos apresentando informações nas quais fusões não foram algo tão inovador na ideia dos mangueboys, mas sim que faziam parte de experimentações

\footnotetext{
${ }^{10}$ Ver: Jornal do Commercio, 16/08/1988, Caderno C. Roteiro, p, 05; Jornal do Commercio 14/01/1989 Caderno C, p. 06.
} 
e ideias que acompanhavam artistas durante a década de 1980. Em outra matéria, desta vez no Diário de Pernambuco (IVANO..., 1985. p. b8), o cantor Ívano diz:

(...) Sinto-me fiel por minha música retratar o Recife e, também, a época em que vivo. Testemunha minha perseverança em ficar desenvolvendo um trabalho altamente baseado nos ritmos do Nordeste como a ciranda e o maracatu, sem fugir da minha profunda dedicação e identificação para com o 'reggae'. Por minha audácia, meu swuing (sic), meu ritmo e minha coragem de falar, sinto-me um guerrilheiro musical, dai o titulo deste show, diz Ívano.

Outras matérias poderiam ser aqui reproduzidas, entabulando discursos de misturas, fusões, ritmos e resgates. Provavelmente, partes dessas matérias foram lidas e alguns desses momentos partilhados por Chico Science, Fred Zero Quatro e Renato L. Viviam em uma cidade permeada por tais discursos. Mas, se tudo é resultado de misturas, o que constituía o Movimento Manguebeat? Além da combinação de ritmos, eram permeados por letras alusivas à politização e formulações de estudiosos de um passado recente, a exemplo de Josué de Castro. Os mangueboys também se apresentavam profundamente concatenados com os elementos da world music. As "tradições populares" foram empregadas como matéria-prima em boa parte das performances dos artistas pernambucanos, e não foi diferente com o Movimento Manguebeat.

Segundo Yudice (2013, p. 28), “A globalização pluralizou os contatos entre os diversos povos e facilitou as migrações, problematizando assim o uso da cultura como um expediente nacional". Percebe-se que os fluxos culturais deslocando-se pelo mundo são dotados de grande intensidade, forçando, em certa medida, o diálogo intercultural, gerando, inevitavelmente, compo- sições entre as várias manifestações culturais locais e aquelas praticadas em outras localidades. De acordo com MUKANA (2008, p. 12-23), Alan Merrian define a música como "um produto do comportamento humano e possui estrutura, mas sua estrutura não pode ter existência própria se divorciada do comportamento que a produz.” As relações entre música, movimentos culturais estão em diálogo permanente, portanto, ocorrem em praticamente todos os espaços onde estão presentes seres humanos.

Que fique claro não serem estas linhas uma tentativa de negar a originalidade do Movimento Manguebeat. Muito pelo contrário! O que este historiador intenta é exatamente mostrar que o Manguebeat não surgiu com um estalar de dedos, ou puramente da ação de Chico ou Fred 04, as atividades de artistas podem ser pensadas como parte, ou seja, com contribuições de outros tempos. As sementes do Manguebeat estão presentes nas experimentações de diversos estilos musicais realizados anteriormente. Os mangueboys certamente escutaram as músicas de Ívano, Valdir Afonjah, Alceu Valença, Ave Sangria, Nação Pernambuco, dentre outros. Assim como presenciaram discursos de que esta ou aquela tradição estava morrendo. Ao que me parece, não penso sozinho, posto que Ivaldo Lima (2010, p. 375), ao se referir ao Manguebeat, já declarava que:

(...) deve-se pensar que este nada mais é do que uma continuidade de movimentos anteriores que lhe proporcionaram um contexto diferenciado, privilegiando músicas baseadas em misturas e fusões. Chico Science por mais iluminado e inteligente que tenha sido, seguramente necessitou ouvir as batidas das afayas do maracatu para perceber a possibilidade de encaixá-las ao som das guitarras distorcidas do rock. Possivelmente leu as matérias de jornal do final dos anos 1980 em que artistas negros, a exemplo de Ívano, propunham a fusão do maracatu com o afoxé e o reggae. 
A proposta é deslocar os olhos para outras possíveis contribuições. Ívano, em entrevista à Agenda Cultural do Recife, em 2009, aponta para o Manguebeat, que obteve uma receptividade que beirou a exaltação (MENDES, 2008, p. 25-29). Pode-se intuir, também, que esses movimentos anteriores, notadamente aqueles em que estavam presentes Ívano e Valdir Afonjá, não possuíam alianças privilegiadas. Se o grupo dos mangueboys atingia a classe média, podemos afirmar que Ívano, Valdir Afonjá, entre outros, tocavam para a 'negrada'. Mais uma vez me apoio em Ivaldo Lima (2010, p. 375) para afirmar que:

$O$ rock se encontrava a toda prova na capital pernambucana, a partir dos espaços alternativos, festivais de escola e bandas que surgiam com propostas diversas, povoando os corações e mentes daqueles interessados e daquelas interessadas em agir, experimentar e criar novos ritmos, sons e movimentos. Tanto Chico Science, como os intelectuais do movimento mangue, foram contemplados com os grupos de rock que lhes antecederam nos anos 1970 e 1980, ao mesmo tempo em que receberam as dádivas dos grupos populares (maracatus nação, maracatus de orquestra, caboclinhos, ursos, bois, troças e clubes de frevo) que lutavam por espaços para existirem e sonharem com dias melhores. Mas nem por isso se pode deixar de lado outros fatores já citados nestas linhas, a exemplo do crescimento de consumo de músicas "exóticas", ou mesmo da abertura de mercado proporcionada pelo crescimento da indústria do turismo local.

Os espaços e contribuições aos quais se refere o historiador acima são os movimentos Udigrudi, dos anos 1970, e a cena local do Recife, na década de 1980. Esses eventos anteriores devem ser pontuados como contribuintes para este movimento? Não como mera continuação ou reprodução, mas como parte de um contexto em que foram sendo gestados. Ou seja, o novo não é assim tão novo, ou, parafraseando o velho guerreiro (Chacrinha), nada se inventa, tudo se copia (e se recria!).

\section{O rock pernambucano agita a cidade}

Diversos jovens que estiveram envolvidos com Movimento Manguebeat estavam envolvidos em festivais proporcionando uma movimentação na cidade do Recife nos anos 1980. Percebemos que o rock produzido nos anos 1980 pode ser pensado como subsídio significativo aos jovens caranguejos. Um espaço congregava, nos finais de semana, as bandas que recentemente tinham sido formadas e as que já possuíam alguma estrada. Esse espaço ficava situado na Avenida Conselheiro Aguiar, bairro de Boa Viagem (zona sul da cidade), e se chamava espaço Arte Viva, que teve importância significativa para o movimento das bandas de rock dos anos 1980. Bandas como N.D.R., Persona, Orion, Câmbio Negro H. C., Realidade Encoberta, The Ax, dentre outras, apresentavam-se no palco deste cenário alternativo. Fundado em 1985, o espaço pertencia a Lurdes Rossiter (A bruxa do Rock), e esse era o cenário em que as bandas de rock se apresentavam. ${ }^{11}$

Pode-se afirmar que, por seus palcos, passaram nomes que, mais tarde, iriam compor bandas do Movimento Manguebeat, a exemplo de Eder o Rocha (a época pertencia à banda Arame Farpado, e posteriormente integrou o Mestre Ambrósio), Niltinho (Alma em Água e Chão e Chinelo), Zero Quatro (Mundo Livre S/A), Chico Science, Lúcio Maia e Dengue (Orla Orbe e Lamento Negro). A banda Devotos (na época acrescida “do Ódio"), também realizou shows neste espaço alternativo do rock recifense. Esse foi o primeiro espaço para muitas bandas da região metropolitana do Recife tocar, e ali tiveram oportunidade de apresentarem pela

\footnotetext{
${ }^{11}$ Ver: TELES, 2010, p. 225-261.
} 
primeira vez. Outros espaços eram frequentados e movimentados no cenário do rock pop na cidade. Como exemplo o Festival Mauritztadt no Sítio da Trindade, localizado na Estada do Arraial, $n^{\circ}$ 3259, em Casa Amarela, zona norte do Recife ${ }^{12}$.

As relações com o Punk Rock inglês da década de 1980 estavam presentes na estética do Movimento dos anos 90, notadamente em termos de atitude, contestação e estética. A banda Mundo Livre S/A possui esta característica bastante próxima com o punk. Chico Science \& Nação Zumbi estabelecem também as filiações do punk rock com o Movimento Manguebeat, conectando 'toda uma produção musical baseada na união de atitude, performance, pop e moda.' (LEÃO, 2002, p. 15). Pensemos juntos agora: esta década é muito importante, uma vez que nela estão bandas que mais tarde irão integrar outros cenários, a exemplo do próprio Movimento Manguebeat.

O Movimento Manguebeat fez sucesso, e esses movimentos anteriores não tiveram tanta repercussão, por quê? Os mangueboys possuíam estreitos laços com pessoas nas mídias locais ${ }^{13}$. Não partimos do pressuposto que apenas isso foi responsável pelo sucesso das bandas, mas que tal relação contribuiu sobremaneira para sua difusão. No caso, o Sistema Jornal do Commercio de Comunicação é praticamente o definidor dessas relações de amizade entre os jornalistas envolvidos com o movimento, e isso ajuda a entender a mídia expressiva que tinham. Certamente isso contribuiu e muito para a visibilidade inicial do movimento, que, provavelmente, ajudou a dar relevo ao que se fazia naquela época (TELES, 2012, p. 263).

O sucesso do Manguebeat não deve ser visto como resultado dessas relações apenas, especialmente pelo fato de que os músicos desta cena serem dotados de exímias qualidades e ideias magistrais, mas, podemos pensar que o capital simbólico destas amizades auxiliara, e muito, na badalação do movimento, o que aparentemente não ocorre com outros jovens artistas na década de 1980. Parcela desse sucesso, seguramente, pode ser depositada na conta da mídia recifense. Com isso, podemos entender que os jornais criaram sentidos (e fatos!) ao noticiarem os shows das bandas, suas festas e movimentações com um entusiasmo nunca antes visto, como pontuou o cantor do campo afro-musical, Ívano (MENDES, 2009). O objeto do jornalista é o tempo presente, imediato e fugaz, e nele deixa suas impressões. Não há total imparcialidade na relação entre jornalista, matéria e objeto, assim como não há em nada daquilo que sofre a ação humana. Mas os jornais são seletivos, e assim é sua atividade porque a matéria deve ser concisa e direta. Por outro lado, o papel da imprensa, nos últimos anos, vem sendo mais do que apenas fonte, sobretudo no tempo presente (CAPELATO, 2014) (GRIJÓ, 2014).

Em diferentes matérias jornalísticas dos primeiros anos da década de 1990, os mangueboys são alçados ao lugar de "salvadores da cultura pernambucana", ou aqueles que iriam dar as condições para que os pernambucanos fizessem frente às 'invasões' da música baiana, que dominava as rádios e os carnavais do período. Não determinam, mas contribuem para moldar práticas e costumes, dando a elas visibilidade e atribuindo valores, além de propiciar espaços de atuação. Os mangueboys ganham espaços em programas de televisão, documentários e vídeoclipes bem antes de seu primeiro Cd, Da Lama ao Caos. Coincidência? Trama orquestrada para uma conspiração? Nada disso. O que há é o engendramento e a materialização de relações entre músicos, homens do palco, e jornalistas, homens das mídias.

\footnotetext{
${ }^{12}$ Ver: Folha de Pernambuco, 08/12/ 1989, p. 11; Folha de Pernambuco, 09/12/ 1989 p. 10.

${ }^{13}$ Podemos ainda perceber que o ciclo de amizades entre os jornalistas Fred Montenegro (Zero Quatro), Renato L e Xico Sá, criam consequentemente a propagação da ideia na mídia.
} 
Esta associação propiciou que interessantes ideias e formulações ganhassem espaço. Não foi por que Chico Science ganhou mídia que ele se tornou genial, mas, por ser versátil e fantástico que teve seus caminhos facilitados. Claro que muitos homens e mulheres virtuoses não tiveram o mesmo destino, mas estou aqui ressaltando que os mangueboys, para além de suas habilidades, tiveram facilidades que outros movimentos não dispuseram.

Como pensar as relações em diversos meios de comunicação, a exemplo da internet, TV e o cinema, sem estabelecer as escolhas e as produções? As músicas de Chico Science, Ívano e Valdir Afonjá eram boas, mas, como explicar o sucesso de uns e a invisibilidade de outros? O que a imprensa viu em Chico Science que não viram em Ívano, Valdir Afonjá, dentre outros? Estamos diante de "um sucesso", fruto da natureza, ou, em outras palavras, o bom, simplesmente por que é bom? Ou é possível dar início a questões a partir da combinação entre gostos, escolhas e construção? Estes meios de comunicação moldam os gostos e a percepção do indivíduo na sociedade. Talvez não intencionais, mas por pura afinidade, mesmo assim inserem e fixam no espectador uma ideia, imagem ou discurso, confirmando o poder da informação. Por meio desta propagação de ideias, estereótipos, clichês e gostos é que se apresenta sob formas "naturalizadas", uma estética e determinados padrões que condicionam o que deve ou não ser consumido (YUDICE, 2013).

É muito comum ouvir dentro dos estudos da história cultural o termo apropriação. Todavia, a cultura é construída no dia a dia por diversos elementos e figuras anônimas em diversos locais. É natural que alguém, em algum lugar ou momento, utilize elementos de outras culturas ou até mesmo outros povos para construir práticas. Às vezes, esses elementos culturais são partilha- $\operatorname{dos}^{14}$. A cultura, da mesma forma, é recriada, as representações ou símbolos antigos em outras representações são atualizados ou recebem outro significado ${ }^{15}$. O papel do historiador que trabalha com a cultural é refletir sobre as práticas em um mundo repleto de representação. Roger Chartier (1990, p. 17), dentre outros livros, escreveu a História Cultural entre Práticas e Representação. Para ele, a representação é construída a partir dos discursos e a maneira de como ele, o discurso, é utilizado por indivíduos e de que forma pontuam suas táticas em relações de poder.:

As representações do mundo social assim construidas, embora aspirem à universalidade de um diagnóstico fundado na razão, são sempre determinadas pelos interesses de grupo que as forjam. Dai, para cada caso, o necessário relacionamento dos discursos proferidos com a posição de quem os utiliza. As percepções do social não são de forma alguma discursos neutros: produzem estratégias e práticas (sociais, escolares, políticas) que tendem a impor uma autoridade à custa de outros, por elas menosprezados, a legitimar um projeto reformador ou a justificar, para os próprios individuos, as suas escolhas e condutas. Por isso esta investigação sobre as representações supõe-nas como estando sempre colocadas num campo de concorrências e de competições cujos desafios se enunciam em termos de poder e de dominação. As lutas de representações têm tanta importância como as lutas econômicas para compreender os mecanismos pelos quais um grupo impõe, ou tenta impor, a sua concepção do mundo social, os valores que são os seus, e o seu domínio.

O problema consiste em determinar o que "é" ou “não é", colocando reputação em ser de determinada maneira ou, em caso negativo, adequar-se a ela. Modelando a percepção de realidade de uma significativa parcela do tecido social. Os que detêm maior poder

\footnotetext{
${ }^{14}$ Ver: CANCLINI, Nestor G. Culturas Hibridas...

${ }^{15}$ Ver: HOBSBAWN, Eric. A invenção das tradições...
} 
simbólico podem construir representações frente a quem não detém tanto capital simbólico, sobretudo na mídia contemporânea (BORDIEU, 1989). Mesmo assim, diversos segmentos se inserem nestes meios tentando quebrar esta massificação e reverter uma lógica imposta principalmente para as massas, empregando táticas para burlar essa dominação. O campo de produção cultural na cidade do Recife nos anos 1990 é parte de uma construção, por meio de discursos da imprensa enaltecendo as realizações de alguns.

Este campo em Pernambuco se constituiu por meio da composição em redes que ligavam os mangueboys a tudo o que estava sendo realizado. O passado recente e suas conexões com as contribuições e ideias propostas ao longo dos anos 1980 por outros artistas, aparentemente estavam esquecidas. Nessas composições, bem como nas alianças, circulavam informações, e assim criou a definição que acompanha o discurso de quem fala sobre a cultura pernambucana na atualidade, de que 'a cena irrompe com o marasmo'. Nesse ínterim, o benefício da dúvida ficou deveras prejudicado. Visto que "os campos de produção cultural propõem, a quem nele está envolvido, um espaço de possíveis", quais sejam as possibilidades que resultam da construção definida, que ganha status de verdade, mas que nada mais é do que representação de uma dita realidade (BOURDIEU, 2011, p. 53-73).

\section{Considerações}

O que ocorre no Recife nesta década é também um dos muitos frutos das reverberações da globalização evidenciada por uma ideia de cosmopolitismo (YUDICE, 2013). Encontramos, no imaginário man- gue, criações e significados para a cidade que passa a se chamar Manguetown, e seus habitantes, os antenados, são os mangueboys e manguegirls. Isso é um dos exemplos do uso dos elementos globalizados, como neste caso de palavras da língua inglesa, definidas por elementos da comunicação global com características da cidade do Recife e o manguezal. O slogan da parabólica fincada na lama representava o que aqueles jovens desejavam, 'Pernambuco em baixo dos pés e a mente na imensidão, ${ }^{, 16}$.

Levando em consideração os argumentos apresentados, o Manguebeat, conforme indicamos anteriormente, não pode ser visto como algo que surge do nada. Ele pode ser entendido como parte de um contexto maior, e pode ser indicado como profundamente integrado e coerente com um continuum maior, em que grupos e movimentos de outrora se fizeram presentes em um cenário extremamente complexo. Não objetivamos esquecer a criatividade, inventividade e esperteza de Chico Science ou Fred Zero Quatro, de forma alguma, mas é praticamente impossível negar que eles integraram um contexto que vinha sendo produzido décadas anteriores na mesma cidade, o Recife. Portanto, a proposta não é retirar ou mesmo contradizer as ideias de um movimento legítimo como foi o Movimento Manguebeat. O lugar em que o Movimento possui na historiografia cultural pernambucana está dado. Não existe anseio em quebrar ou macular esse lugar. Muito menos aspiração em criar promoção para qualquer grupo. O importante para o artigo é propor um debate em torno de contribuições em diversas frentes. A proposta é ampliar e contribuir com debates em torno da criatividade musical e cultural neste 'caldeirão' cultural que é Pernambuco.

\footnotetext{
${ }^{16}$ Chico Science. Mateus Enter. Chico Science e Nação Zumbi. Afrociberdelia. Rio de Janeiro: Chaos/Sony Music, 1996. Faixa 1.
} 


\section{Referências}

BORDIEU, Pierre. O poder simbólico. Lisboa: Difel, 1989.

BOURDIEU, Pierre. Por uma ciência das Obras. In: Razões Práticas: sobre a teoria da ação. $11^{\text {a }}$ Ed. Campinas, SP: Papirus, 2011.

CAPELATO, Maria Helena. 'História do tempo presente: a grande imprensa como fonte e objeto de estudo'. In. DELGADO, Lucília de Almeida, FERREIRA, Marieta de Moraes. (Org.) História do tempo presente. Rio de Janeiro: Editora FGV, 2014.

DELGADO, Lucília de Almeida, FERREIRA, Marieta de Moraes. (Org.) História do tempo presente. Rio de Janeiro: Editora FGV, 2014.

GIRON, Luís Antônio. Chico Science "envenena” o maracatu. Folha de São Paulo. Ilustrada. 31 de março de 1994, p. 5.

GRIJÓ, Luiz Alberto. 'A mídia brasileira no século XXI: desafio da pesquisa histórica'. In:

LEÃO, Carolina Carneiro. A maravilha mutante: batuque, sampler e pop no Recife dos anos 90. Dissertação (Mestrado) em Comunicação pela UFPE, Recife, 2002.

LIMA, Ivaldo Marciano de França. Entre Pernambuco e a África. História dos maracatus nação e a espetacularização da cultura Popular. Tese (Doutorado) em História pela UFF, Niterói, 2010.

LINS, Renato. Não. Diário de Pernambuco 03/05/1999, caderno Viver, p. 1

MENDES, Felipe. Entrevista com Ívano. Agenda Cultural Prefeitura do Recife, Secretaria da fundação de Cultura. Ano $14 \mathrm{n}^{\circ} 172$, dezembro de 2009.

MUKUNA, Kazadi wa. Sobre a busca da verdade na etnomusicologia. Um ponto de vista. Revista USP, São Paulo, n.77, p. 12-23, março/maio 2008.

NETO, Moisés. Chico Science: rapsódia afrociberdélica. Recife, 2001: Edições Ilusionistas, 2000.

. Chico Science: Zeroquatro \& Faces do Suburbio. Recife, 2001: Edições Ilusionistas, 2006.

QUEIROS, Martha Rosa Figueira. Onde cultura é politica: movimento negro, afoxés e maracatus no carnaval do Recife (1979-1995). Tese (Doutorado) em História pela Unb, Brasília, 2010.

REVEL, Jacques. Microanálise e construção do social. In: REVEL, Jacques. (org). Jogos de Escalas - a experiência da microanálise. Rio de Janeiro: FGV Editora, 1998.

TELES, José. O malungo Chico Science. Recife: ed. Bagaço. 2003.

. Do frevo ao manguebeat. $2^{\text {a }}$ edição. São Paulo: Ed 34. 2012.

YUDICE, George. A conveniência da cultura: Usos da cultura na era global. $2^{\mathrm{a}}$ Ed. Belo Horizonte, Editora UFMG, 2013.

\section{Apêndice}

BANDAS rejeitam rótulo mangue. Folha de Pernambuco, Caderno Programa capa, p. 1, 07/05/1999.

DUNEMAN, Jeffrey S. To modernize the past: Chico Science \& Nação Zumbi, the Mangue Movement, and Cultural Rejuvenation in Recife, Pernambuco, Brazil. Thesis (M.A.), Latin American Studies, The University of New Mexico. Albuquerque, New Mexico, 2002.

GALINSKY, Philip. Maracatu Atômico: Tradition, Modernity, and Postmodernity in the Mangue Movement and "New Music Scene" of Recife, Pernambuco, Brazil. Thesis (Phd). Wesleyan University. Middletown, Connecticut, 1998. 
ÍVANO faz show na Casa da Cultura. Jornal do Commercio, 01/02/1987, Caderno C, p. 07.

ÍVANO guerrilheiro no Teatro do Parque, Diário de Pernambuco, 03/11/1985. p. b8.

ÍVANO faz show na Casa da Cultura. Jornal do Commercio, 01/02/1987, Caderno C, p. 07.

LIMA, Ivaldo Marciano de França. Maracatus do Recife: novas considerações sob o olhar dos tempos. Recife: Edições Bagaço, 2012.

MARACATU Panacéia S/A. Jornal do Commercio. 20/01/1985, Cultural, Caderno C, p. 04.

MARACATU, teatro, Diário Pernambuco, 08/01/1985, p. b6.

NOITE Afro-Olindense e Opção de amanhã no Centro de Arte. Jornal do Commercio. 07/02/1987, Caderno C. p. 06.

NASCIMENTO, Francisco Gerardo Cavalcante do. Manguebit: Diversidade na Indústria Cultural Fonográfica Brasileira da década de 1990. Dissertação (Mestrado) em História pela UECE, Fortaleza, 2010.

NETO, Moisés. Manguetown: A Representação do Recife (PE) na Obra de Chico Science e Outros Poetas do Movimento Mangue (“A Cena Recifense dos Anos 90”). Dissertação (Mestrado) em Teoria da Literatura pela UFPE, Recife, 2003.

OLIVEIRA, Esdras Carlos de Lima. Artífices da Manguetown: A constituição de um novo campo artístico no Recife (1991-1997). Dissertação (Mestrado) em História Social da Cultura Regional pela UFRPE, Recife, 2012.

RIBEIRO, Getúlio. Do tédio ao caos, do caos a lama: os primeiros capítulos da cena Mangue Recife 1984-1991. Dissertação (Mestrado) em História pela UFU, Uberlândia MG, 2007.

SILVEIRA, Roberto Azoubel da Mota. Mangue: uma ilustração da grande narrativa pós-moderna. Dissertação (Mestrado) em Letras pela PUC-Rio, Rio de Janeiro, 2002.

SALEM, Rodrigo. Falta de autocrítica no mangue. Diário de Pernambuco, 19/04/2000, Caderno Viver, p. 06.

SALEM, Rodrigo. Artistas discutem o futuro do movimento manguebeat. Diário de Pernambuco, 03/05/1999, caderno Viver, p. 1.

SANTOS, Humberto. Sim. Diário de Pernambuco 03/05/1999, caderno Viver, p. 1.

TIMBU promete enfezar-se com maracatu no carnaval, Diário Pernambuco. 13/02/1985, p. a5.

TIMBU Coroado volta como uma das atrações pelas ruas do Recife, Diário Pernambuco, 20/02/1985 p. a15.

VALDIR Afonjá mostra em disco Negra Magia. Jornal do Commercio, 16/08/1988, Caderno C. Roteiro, p, 05.

VALDIR Afonjá faz novo show. Jornal do Commercio 14/01/1989 Caderno C, p. 06.

Submissão: 27/07/2016 Aceite: $14 / 01 / 2017$ 